\section{Carmen García-Ruiz Maria Luisa Marina}

Departamento de Química Analítica, Facultad de Química, Universidad de Alcalá, Alcalá de Henares (Madrid), Spain

\title{
Fast enantiomeric separation of basis drugs by electrokinetic chromatography. Application to the quantitation of terbutaline in a pharmaceutical preparation
}

\begin{abstract}
Electrokinetic chromatography (EKC) using micelles of bile salts alone or mixed with sodium dodecyl sulfate (SDS) and neutral, anionic, or cationic cyclodextrins (CDs) in the separation buffer has been employed in order to achieve fast enantiomeric separation of basic drugs. A study of the enantiomeric separation ability of these chiral selectors concerning four basic drugs (epinephrine, terbutaline, clenbuterol, and salbutamol) has been carried out under different experimental conditions. The best chiral selectors to perform the enantiomeric separation of these drugs were neutral $\beta-C D$ derivatives, specifically permethylated $\beta-C D$ PM- $\beta-C D$. The effect of the PM- $\beta-C D$ concentration, temperature, and applied voltage on the enantiomeric resolution of the basic drugs was investigated. The use of a $25 \mathrm{~mm}$ ammonium acetate buffer ( $\mathrm{pH} 5.0$ ), $30 \mathrm{~mm}$ in PM-B-CD together with an applied voltage of $20 \mathrm{kV}$ and a temperature of $15^{\circ} \mathrm{C}$ enabled the individual and fast enantiomeric separation of epinephrine, norepinephrine, terbutaline, clenbuterol, and salbutamol each one into its two enantiomers in less than $3 \mathrm{~min}$. The EKC method was validated (precision and accuracy) to quantitate terbutaline in a pharmaceutical preparation, obtaining a limit of detection of $4 \mu \mathrm{g} / \mathrm{mL}$.
\end{abstract}

Keywords: Enantiomeric separation / Chiral basic drugs / Electrokinetic chromatography / Terbutaline / Method development / Method validation

EL 4559

\section{Introduction}

When a drug is administered as racemic mixture, frequently one enantiomer has the pharmacological effects while the other could have no or little effects or it could show some undesired side effects. These reasons have promoted the general policy of marketing single enantiomer drugs wherever possible. Accordingly, it is interesting to develop analytical methods for chiral analysis to separate the enantiomers of chiral drugs. In this regard, capillary electrophoresis (CE) has experienced an enormous growth in the field of chiral separations due to its high separation efficiency and flexibility. Specifically, a mode of CE known as electrokinetic chromatography (EKC), based on the partitioning of the analytes between the

Correspondence: Dr. Maria Luisa Marina, Departamento de Química Analítica, Facultad de Química, Universidad de Alcalá, Ctra. Madrid-Barcelona Km. 33.600, 28871 Alcalá de Henares (Madrid), Spain

E-mail: mluisa.marina@uah.es

Fax: 34-91-8854971

Abbreviations: $\quad \boldsymbol{\beta}-\mathrm{CD}-\mathrm{NH}_{2}, \quad 6$-monodeoxi-6-monoamino- $\beta$ cyclodextrin; CM- $\beta$-CD, carboxymethylated $\beta$-cyclodextrin; HP- $\boldsymbol{\beta}-\mathbf{C D}$, (2-hydroxy)propyl $\beta$-cyclodextrin; PM- $\boldsymbol{\beta}-\mathbf{C D}$, permethylated $\beta$-cyclodextrin; STC, taurocholic acid sodium salt; STDC, taurodeoxycholic acid sodium salt; Succ- $\beta-C D$, succinylated $\beta$-cyclodextrin buffer solution and a pseudophase, has been widely employed to obtain chiral separations by CE when a chiral selector capable of recognizing both enantiomers stereoselectively has been used [1-5].

For the separation of different chiral basic drugs, the experimental conditions most employed in EKC are acidic $\mathrm{pHs}$ (from 2.2 to 4.0) with neutral CDs such as $\beta-C D$, heptakis(2,6-di-O-methyl)- $\beta$-CD (DM- $\beta-C D)$, hydroxypropyl$\beta-C D(\mathrm{HP}-\beta-\mathrm{CD})$, heptakis(2,3,6-tri-O-methyl)- $\beta-\mathrm{CD}$ (TM$\beta-C D)$, hydroxyethyl- $\beta-C D$ (HE- $\beta-C D)$ [6-28], with DM- $\beta-$ $C D$ being the most effective and employed chiral selector $[10,11,13-15,17,20,27,28]$. Anionic CDs (sulfated $\beta-C D$, sulfobutyl ether $\beta-C D$, carboxyethyl- $\beta-C D$, carboxymethyl- $\beta-C D$, heptakis-6-sulfato $\beta-C D$ ) have also been employed at acidic pHs (from 2.5 to 5.8) [8, 16, 19, 2934] for the enantioseparation of basic drugs. Only in one work neutral $\mathrm{pH}$ and an anionic or a cationic CD synthesized were employed by the authors to enantioseparate terbutaline and salbutamol [35]. In all these works, the analysis times ranged from 7 to $53 \mathrm{~min}$, with the exception of two cases $[9,10]$ which were about 4 min. Nevertheless, although the number of publications dealing with the use of CDs in CE for the enantiomeric resolution of basic chiral drugs is considerable, there are few reports concerning the area of quantitation and/or validation of chiral methods [21, 22, 27, 34, 36]. Therefore, it seems interesting to test new CDs and experimental conditions 
in order to achieve a rapid enantioseparation of basic chiral drugs and to validate this method to analyze them in commercial formulations.

The aim of this work was the selection of experimental conditions enabling a fast enantiomeric separation of a group of chiral basic drugs. The drugs studied in this work, have different pharmacological effects. Norepinephrine and epinephrine are sympathomimethic drugs with several pharmacological activities and clenbuterol, terbutaline, and salbutamol are $\beta$-agonists clinically used as bronchodilators [37]. A systematic evaluation of several chiral selectors (including micelles of bile salts alone or mixed with SDS and neutral, anionic, or cationic CD derivatives) in different separation media was carried out. In addition, the influence of experimental conditions such as the concentration of the chiral selector, temperature, and applied voltage on the enantiomeric separation of the basic drugs studied was investigated for the best chiral selector. Finally, the CE method was validated (in terms of precision and accuracy) in order to quantitate terbutaline in a pharmaceutical preparation.

\section{Materials and methods}

\subsection{Chemicals and samples}

All reagents were of analytical grade. 2-(N-Cyclohexylamino)ethanesulfonic acid (CHES), taurocholic acid sodium salt (STC), taurodeoxycholic acid sodium salt (STDC), and cholic acid sodium salt (SC) were purchased from Sigma (St. Louis, MO, USA); sodium dihydrogen phosphate, dimethyl sulfoxide (DMSO), and sodium hydroxide were supplied from Merck (Darmstadt, Germany); deoxycholic acid sodium salt (SDC), sodium tetraborate, ammonium acetate, $\beta-C D$, and $\gamma-C D$ were from Fluka (Buchs, Switzerland); HP- $\beta-C D$ (degree of substitution DS 3), permethylated $\beta-C D$ (PM- $\beta-C D$, DS 12-13), carboxymethylated $\gamma-\mathrm{CD}(\mathrm{CM}-\gamma-\mathrm{CD}$, DS $\sim 3$ ), carboxymethylated $\beta-C D(C M-\beta-C D$, DS $\sim 3$ ), succinylated $\gamma-C D$ (Succ- $\gamma-C D$, DS $\sim 3$ ), and succinylated $\beta$-CD (Succ- $\beta$-CD, DS 3.5), $\beta$-CD sulfated ( $\beta$-CD sulfated, DS $\sim 12$ ), $\beta-C D$ phosphated ( $\beta-C D$ phosphated, DS 6), and 6-monodeoxi-6-monoamino- $\beta$-CD ( $\beta$-CD$\mathrm{NH}_{2}$, DS $=1$ ) were obtained from Cyclolab (Budapest, Hungary). Water used to prepare solutions was purified through a Milli-Q system from Millipore (Bedford, MA, USA). All solutions were filtered through $45-\mu \mathrm{m}$ pore-size disposable nylon filters from Scientific Resources (Eatontown, NJ, USA). Salbutamol, clenbuterol, norepinephrine, and terbutaline were purchased from Sigma. Epinephrine was supplied by Aldrich (St. Louis, MO, USA). The structures of these basic drugs are shown in Fig. 1. A pharma-<smiles>CNCC(O)c1ccc(O)c(O)c1</smiles><smiles>NCC(O)c1ccc(O)c(O)c1</smiles><smiles>CC(C)(C)NCC(O)c1cc(Cl)c(N)c(Cl)c1</smiles>

Salbutamol<smiles>CC(C)(C)NCC(O)c1cc(O)cc(O)c1</smiles><smiles>CC(C)(C)NCC(O)c1ccc(O)c(CO)c1</smiles>

Figure 1. Structures of the chiral basic drugs studied in this work.

ceutical preparation (a syrup) containing terbutaline sulfate with excipients (sorbitol, glycerine, sodium citrate, sodium benzoate, disodium edetate, aroma of raspberry and lemon, and distilled water) was acquired from a chemist at Alcalá de Henares (Madrid, Spain).

\subsection{Apparatus}

A HP ${ }^{3 D}$ CE system (Hewlett-Packard, Waldbronn, Germany) equipped with an on-column diode array detector (DAD) and an HP 3D-CE Chemstation software was used. An uncoated fused-silica capillary from Composite Metal Services (Worcester, England) with $50 \mu \mathrm{m}$ inner diameter (ID) and $375 \mu \mathrm{m}$ outer diameter (OD) with an effective length of $25 \mathrm{~cm}$ (33.5 cm total length) was employed. Capillary temperature was varied from 15 to $45^{\circ} \mathrm{C}$ and UV detection was performed at $230 \mathrm{~nm}$. Electrolytic solutions were degassed in an ultrasonic cleaner KM from Raypa (Barcelona, Spain). A 654 pH-meter from Metrohm (Herisau, Switzerland) was employed to adjust the $\mathrm{pH}$ of the separation buffers.

\subsection{Procedure}

Electrolytic solutions were prepared in two steps: (i) weighing and dissolving the appropriate amount of buffer in Milli-Q water to obtain the required concentration and adjusting the $\mathrm{pH}$ to the desired value with $1 \mathrm{~m}$ sodium hydroxide or $1 \mathrm{~m}$ hydrochloric acid solutions and (ii) adding $10 \mathrm{~mL}$ of the buffer solution to the desired amount of chiral selector (bile salts with or without SDS or neutral $C D$ derivatives). When charged $C D$ derivatives were used in the separation buffer, the final step was to adjust the $\mathrm{pH}$ to the desired value due to the acid or basic prop- 
erties of these CD derivatives. Standard solutions were prepared by dissolving each basic drug in DMSO up to a final concentration of $1000 \mathrm{ppm}$. Finally, dilutions of this solution in DMSO were made in order to obtain the required concentration. The determination of the terbutaline content in the pharmaceutical preparation (a syrup) required a dilution of $40 \mu \mathrm{L}$ of the syrup in a final volume of $300 \mu \mathrm{L}$ with DMSO. The resulting solution was directly injected into the electrophoretic system. For the validation of the method, different sample solutions were prepared by diluting different amounts of the syrup in DMSO in order to obtain the desired concentration. Between injections, the capillary was washed with $0.1 \mathrm{M} \mathrm{NaOH}$ for $2 \mathrm{~min}$ followed by the separation buffer for $4 \mathrm{~min}$. The injection was made by pressure: $30 \mathrm{mbar}$ for $2 \mathrm{~s}$ of sample (50 mbar for $5 \mathrm{~s}$ in the validation of the method applied to the quantitation of terbutaline) followed by 30 mbar for $2 \mathrm{~s}$ of separation buffer. The applied voltage ranged from 15 to $25 \mathrm{kV}$.

\subsection{Data treatment}

Enantiomeric resolution was calculated by Eq. (1):

$R_{\mathrm{s}}=1.18\left(t_{2}-t_{1}\right) /\left(w_{1}+w_{2}\right)$

where $t_{1}$ and $t_{2}$ are the two enantiomers migration times and $w_{1}, w_{2}$ are the peak widths at half-height of the corresponding peaks. All the experimental data were manipulated using Excel 7.0 from Microsoft Office software [38].

\section{Results and discussion}

\subsection{Fast enantiomeric separation of basic drugs: selection of the experimental conditions}

Four chiral basic drugs (epinephrine, terbutaline, clenbuterol, and salbutamol) have been injected in a CE system using different chiral selectors: bile salts alone or mixed with SDS and neutral, anionic, or cationic CDs, in the separation buffer. All conditions used in this work to try the enantiomeric separation of these compounds are summarized in Table 1. First, the four basic drugs were injected in three different buffers: $25 \mathrm{~mm}$ borate $(\mathrm{pH} 9)$, phosphate $(\mathrm{pH} 7)$, or acetate ( $\mathrm{pH} 5)$ using bile salts (SC, STC, SDC, and STDC) as chiral selectors. When bile salts alone or with SDS were used, no chiral recognition was observed for any of the basic drugs studied (Table 1). Second, different CD derivatives (neutral, anionic, and cationic) were used under different experimental conditions in order to achieve the enantiomeric separation of the basic drugs studied. Two different buffers were used
Table 1. Experimental conditions tested for the enantiomeric separation of the basic drugs studied ${ }^{\text {a) }}$

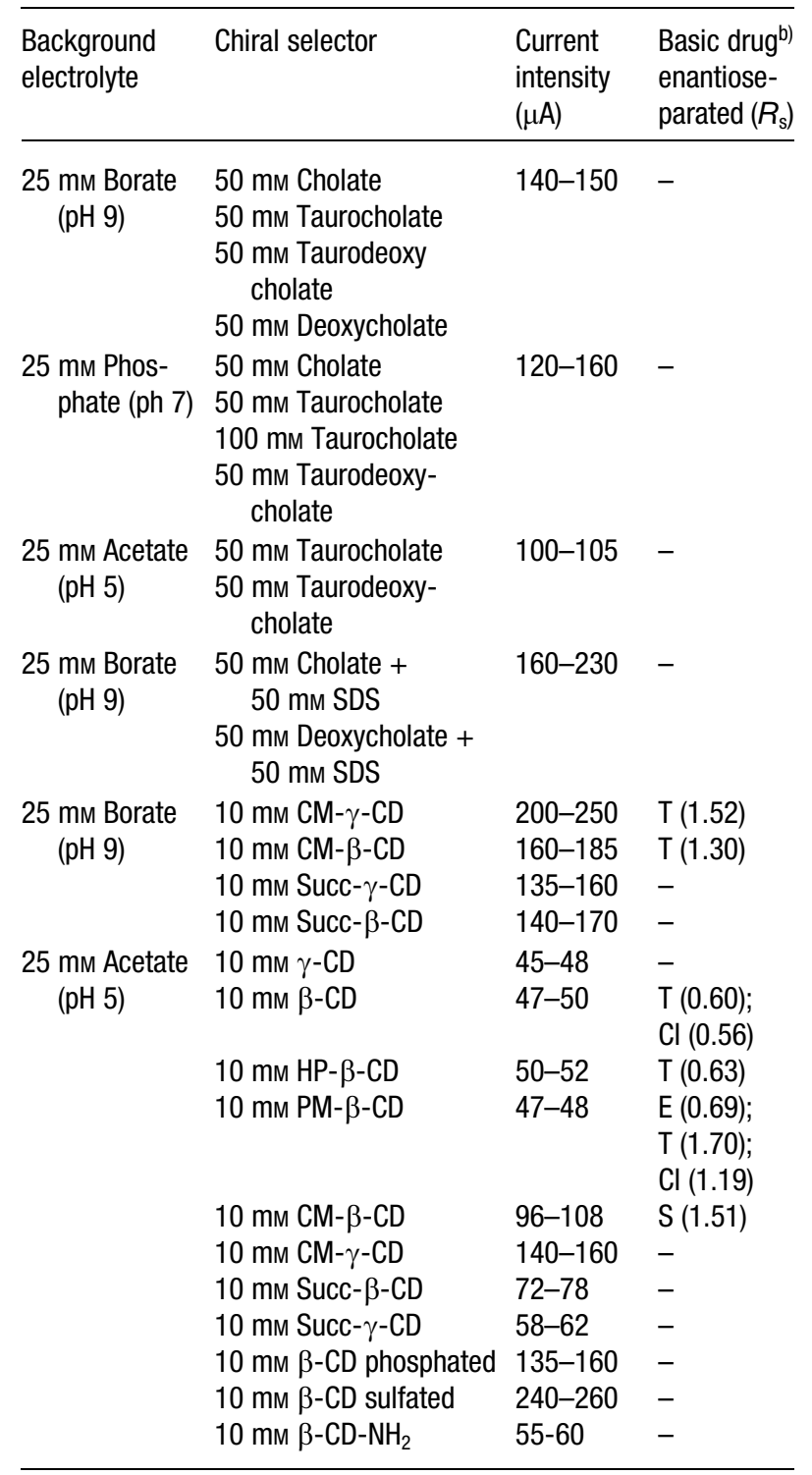

a) Conditions: uncoated fused-silica capillary, $33.5 \mathrm{~cm}$ (25 $\mathrm{cm}$ to the detector) $\times 50 \mu \mathrm{m}$ ID; UV detection at $230 \mathrm{~nm} ; 25^{\circ} \mathrm{C}$ and $20 \mathrm{kV}$

b) $\mathrm{E}$, epinephrine; $\mathrm{S}$, sabutamol; $\mathrm{T}$, terbutaline; $\mathrm{Cl}$, clenbuterol

with a fixed concentration (10 mM) of different CD derivatives (Table 1). When different anionic CD derivatives (CM$\gamma-C D, C M-\beta-C D$, Succ- $\gamma-C D$, Succ- $\beta-C D$ ) were used in a $25 \mathrm{~mm}$ borate buffer ( $\mathrm{pH} 9$ ), only CM- $\beta-\mathrm{CD}$ or $\mathrm{CM}-\gamma-\mathrm{CD}$ enabled the enantioseparation of terbutaline. In this case, the peaks of the enantiomers were after the peak of the electroosmotic flow (EOF) being both signals partially overlapped for $\mathrm{CM}-\gamma-\mathrm{CD}$. Then, a $25 \mathrm{~mm}$ acetate buffer $(\mathrm{pH} 5)$ was employed with neutral $(\gamma-\mathrm{CD}, \beta-\mathrm{CD}$, 


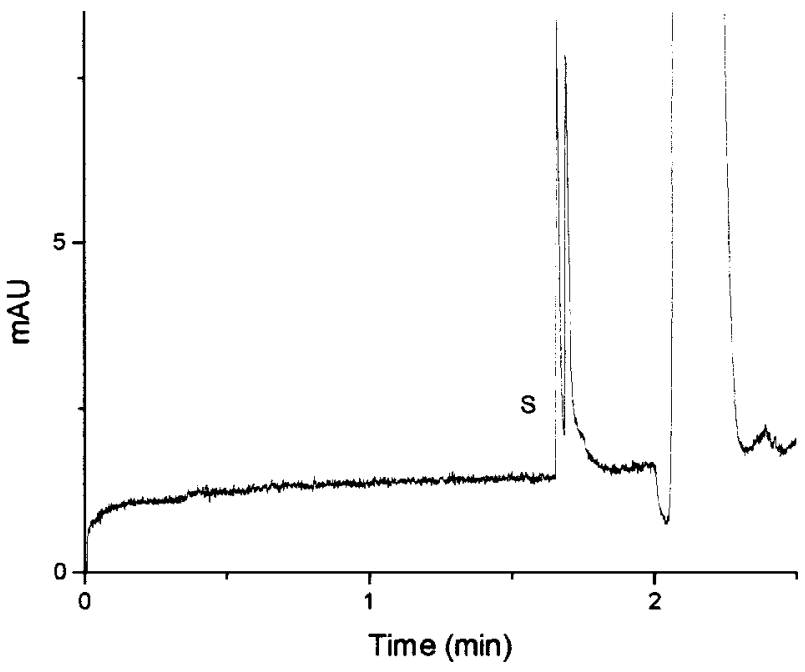

Figure 2. Enantiomeric separation of salbutamol in a $25 \mathrm{~mm}$ acetate buffer ( $\mathrm{pH}$ 5) with $10 \mathrm{~mm}$ CM- $\beta$-CD. Experimental conditions: temperature $25^{\circ} \mathrm{C}$; applied voltage $20 \mathrm{kV}$; UV detection at $230 \mathrm{~nm}$; injection by pressure, $30 \mathrm{mbar}$ for $2 \mathrm{~s}$ sample followed by 30 mbar for $2 \mathrm{~s}$ buffer; $50 \mu \mathrm{m} \mathrm{ID}, 375 \mu \mathrm{m}$ OD capillary of $33.5 \mathrm{~cm}$ length $(25 \mathrm{~cm}$ to the detector).

HP- $\beta-C D, \quad P M-\beta-C D)$, anionic (CM- $\beta-C D, C M-\gamma-C D$, Succ- $\beta-C D$, Suc- $\gamma-C D, \beta-C D$ phosphated, and $\beta-C D$ sulfated), and cationic ( $\left.\beta-\mathrm{CD}-\mathrm{NH}_{2}\right) \mathrm{CD}$ derivatives. From the charged CD derivatives employed with acetate buffer at $\mathrm{pH} 5$, only $\mathrm{CM}-\beta-\mathrm{CD}$ enabled a rapid enantioseparation of salbutamol (Fig. 2). Nevertheless, with the neutral $\beta-C D$ derivatives HP- $\beta-C D, \beta-C D$, and $P M-\beta-C D$ one or more than one basic drug was enantiomerically separated. Specifically, when $10 \mathrm{~mm}$ PM- $\beta$-CD was employed in a $25 \mathrm{~mm}$ acetate buffer $(\mathrm{pH} 5)$ the enantiomeric separation of a higher number of compounds (epinephrine, terbutaline, and clenbuterol) was achieved. Therefore, under the above-mentioned conditions, the influence of several experimental parameters such as the concentration of the chiral selector, the temperature, and the applied voltage on the enantiomeric separation of the basic drugs was investigated.

Figure $3 a$ shows the variation of the enantiomeric resolution obtained for epinephrine, terbutaline, clenbuterol, and salbutamol as a function of the PM- $\beta-C D$ concentration in a $25 \mathrm{~mm}$ acetate buffer ( $\mathrm{pH} 5)$. It can be observed that the most appropriate concentration to achieve the higher enantiomeric resolution for the three basic drugs enantioseparated is $30 \mathrm{~mm}$ of PM- $\beta-C D$. But this concentration of $P M-\beta-C D$ led to enantiomeric resolutions comprised between 1.1 and 1.5 for epinephrine, terbutaline, and clenbuterol and no enantioseparation was observed for salbutamol, for which the effect of temperature and applied voltage was studied in order to obtain increasing
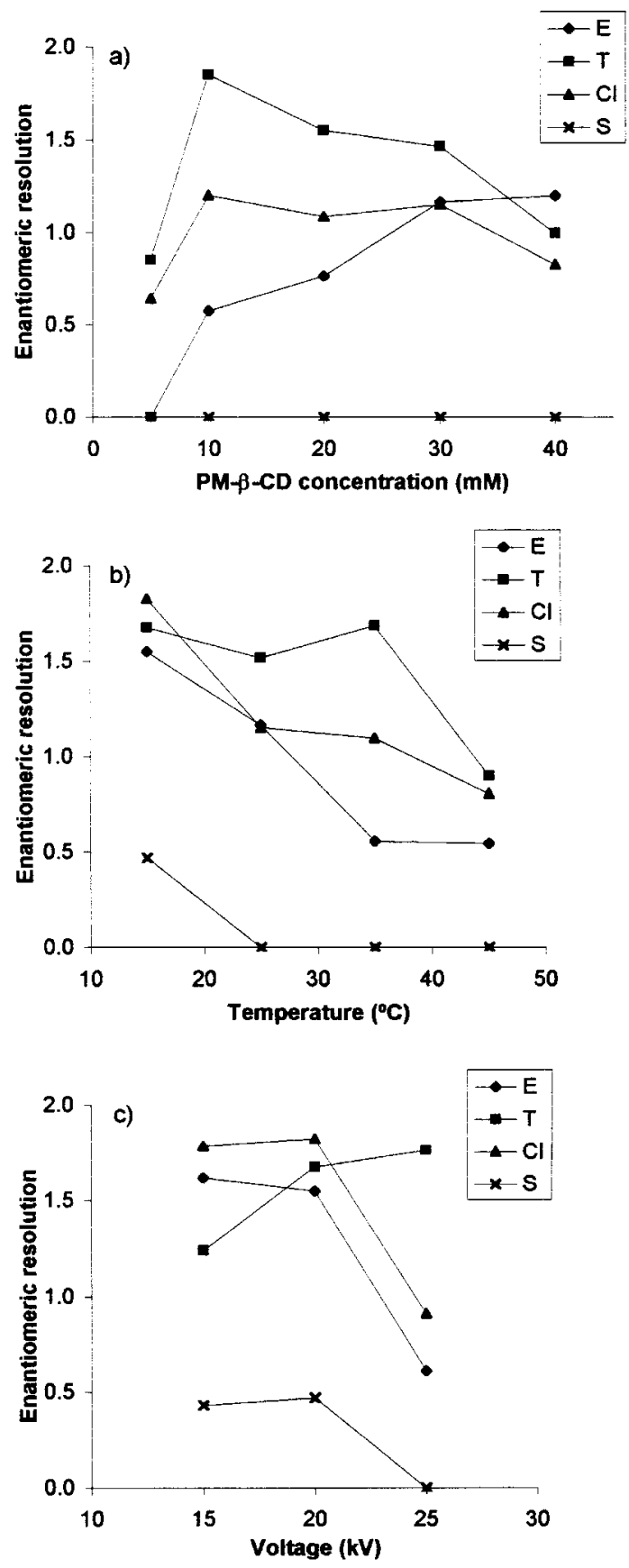

Figure 3. Variation of the enantiomeric resolution for epinephrine $(E)$, terbutaline $(T)$, clenbuterol $(\mathrm{Cl})$, and salbuta$\mathrm{mol}(\mathrm{S})$ in a $25 \mathrm{~mm}$ acetate buffer $(\mathrm{pH} \mathrm{5})$ as a function of: (a) the PM- $\beta-C D$ concentration at $25^{\circ} \mathrm{C}$ and $20 \mathrm{kV}$; (b) the temperature using $30 \mathrm{~mm} P M-\beta-C D$ and $20 \mathrm{kV}$; and (c) the applied voltage using $30 \mathrm{~mm}$ PM- $\beta-C D$ and $15^{\circ} \mathrm{C}$. Other experimental conditions as in Fig. 2.

enantiomeric resolutions. The variation of the enantiomeric resolution of epinephrine, terbutaline, clenbuterol, and salbutamol in a $25 \mathrm{~mm}$ acetate buffer $(\mathrm{pH} 5)$ with $30 \mathrm{~mm}$ PM- $\beta-C D$ as a function of the temperature is 


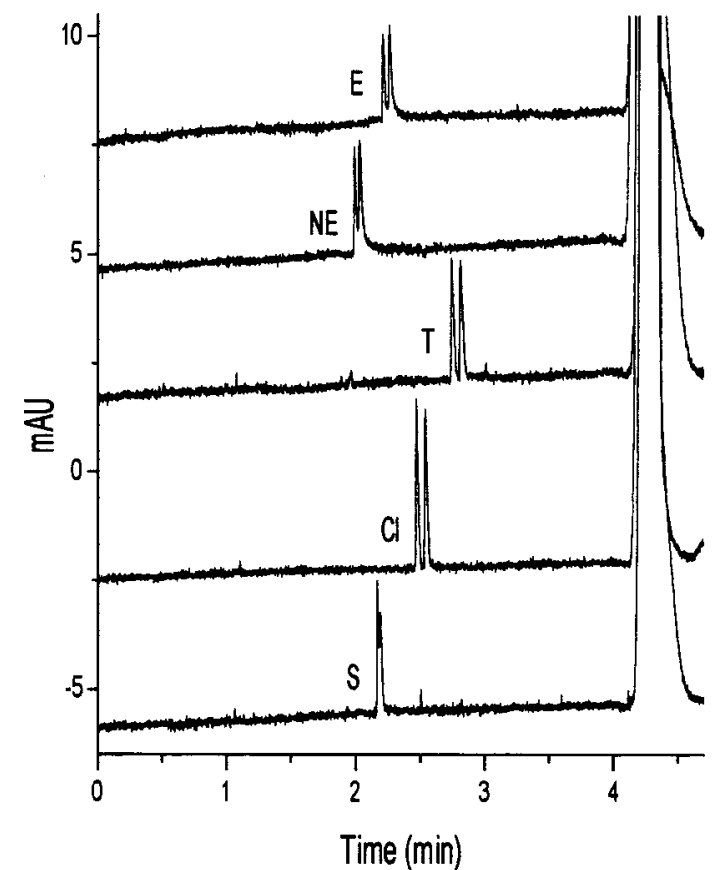

Figure 4. Enantiomeric separation of epinephrine $(E)$, norepinephrine (NE), terbutaline $(\mathrm{T})$, clenbuterol $(\mathrm{Cl})$, and salbutamol (S) by EKC in a $25 \mathrm{~mm}$ acetate $(\mathrm{pH} 5)$ buffer containing $30 \mathrm{~mm} P M-\beta-C D$ at $15^{\circ} \mathrm{C}$ and $20 \mathrm{kV}$. Other experimental conditions as in Fig. 2.

shown in Fig. 3b. An increase can be observed in the enantiomeric resolution when the temperature was decreased. This fact, also observed for a group of chiral dihydropyridines of pharmaceutical interest [39], could be due to the increase in the stability of selector-selectand complexes that takes place when the temperature is decreased [1].

Since all the experiments described before were carried out at a constant applied voltage of $20 \mathrm{kV}$, a $25 \mathrm{~mm}$ acetate buffer $(\mathrm{pH} 5)$ containing $30 \mathrm{~mm} P M-\beta-\mathrm{CD}$ at $15^{\circ} \mathrm{C}$ was used in order to study whether a variation of the applied voltage could enhance the chiral separation of the basic drugs studied. Figure $3 \mathrm{c}$ shows the variation of the enantioresolution of epinephrine, terbutaline, clenbuterol, and salbutamol as a function of the applied voltage that was varied from 15 to $25 \mathrm{kV}$. It can be observed that the highest enantiomeric resolution for the four basic drugs enantioseparated was obtained at an applied voltage of $20 \mathrm{kV}$. The selected conditions ( $25 \mathrm{~mm}$ acetate buffer, $\mathrm{pH} 5$, $30 \mathrm{~mm}$ PM- $\beta-\mathrm{CD}$ at $15^{\circ} \mathrm{C}$ and an applied voltage of $20 \mathrm{kV}$ ) were applied to perform the enantiomeric separation of norepinephrine. The fast enantiomeric separation, in less than $3 \mathrm{~min}$, of epinephrine, norepinephrine, terbutaline, clenbuterol, and salbutamol was performed (Fig. 4), although for salbutamol no baseline resolution was obtained.

\subsection{Validation of the EKC method for the quantitation of terbutaline in a pharmaceutical preparation}

Due to the short analysis time required for the enantiomeric separation of terbutaline with the CE system constituted by $25 \mathrm{~mm}$ acetate buffer at $\mathrm{pH} 5$ with $30 \mathrm{~mm}$ PM$\beta-C D$ at $15^{\circ} \mathrm{C}$ and $20 \mathrm{kV}$, the validation of this method was performed for the quantitation of terbutaline in a pharmaceutical preparation, used as bronchodilator in patients with asthma, bronchitis, emphysema and, in general, breathing diseases with bronchoconstriction. The quantitative analysis of terbutaline in the pharmaceutical preparation (a syrup) was performed using the external standard method for calibration. Linear relationships were obtained for the variation of the total peak area (the addition of the areas corresponding to the first and the second migrating enantiomers) as a function of the concentration of terbutaline standard. Good linear correlations $(r>$ 0997) could be observed when eight concentrations (5, $15,30,60,100,120,160$, and $200 \mu \mathrm{g} / \mathrm{mL}$ of terbutaline in DMSO) were used for the calibration plot. The sensitivity of the EKC method for terbutaline, evaluated as the slope of the straight line obtained, was $0.35 \mathrm{~mL} / \mu \mathrm{g}$. The limit of detection was calculated as the concentration corresponding to a signal-to-noise ratio of 3 . The noise was estimated as the largest deviation of the detector signal from the baseline measured in a section of about $2 \mathrm{~min}$ in the absence of analyte and at $230 \mathrm{~nm}$ [40]. The limit of detection calculated for terbutaline was about $4 \mu \mathrm{g} / \mathrm{mL}$. Figure 5 shows the electropherogram corresponding to the signal obtained for the pharmaceutical preparation diluted in DMSO up to $10 \mu \mathrm{g} / \mathrm{mL}$.

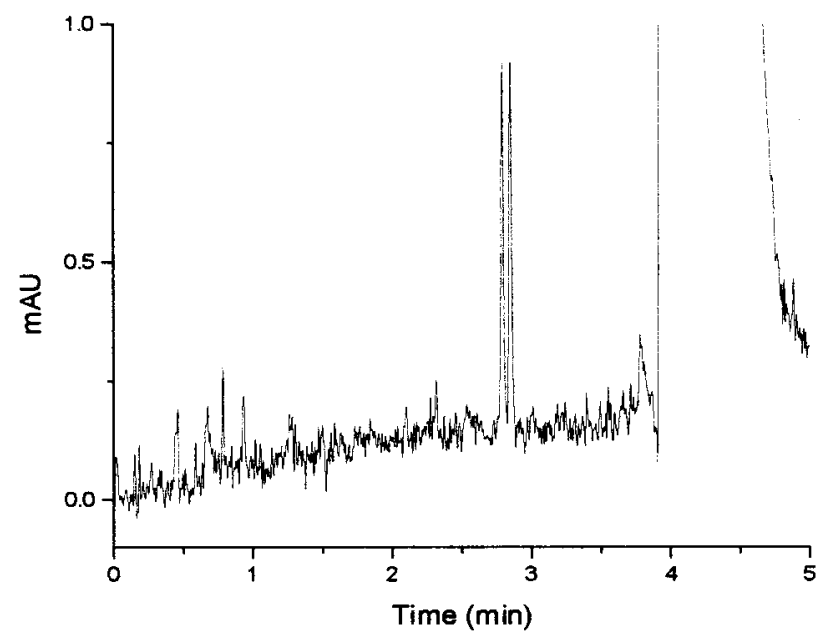

Figure 5. Enantiomeric separation of the terbutaline contained in a pharmaceutical preparation (a syrup diluted in DMSO up to $10 \mu \mathrm{g} / \mathrm{mL}$ ) in a $25 \mathrm{~mm}$ acetate buffer (pH 5) containing $30 \mathrm{~mm} P M-\beta-C D$ at $15^{\circ} \mathrm{C}$ and $20 \mathrm{kV}$; pressure injection, 50 mbar for $5 \mathrm{~s}$ sample followed by $30 \mathrm{mbar}$ for $2 \mathrm{~s}$ buffer. Other experimental conditions as in Fig. 2. 
Table 2. Precision of peak areas and migration times for terbutaline enantiomers and terbutaline content in a commercial syrup (calibration by the external standard method) by the CE method $^{\text {a) }}$

\begin{tabular}{cccccccc}
\hline Precision & $\mathrm{C}_{\mathrm{s}}^{\mathrm{b})}$ & $\begin{array}{l}\mathrm{RSD} \\
(\mathrm{A} 1)\end{array}$ & $\begin{array}{l}\mathrm{RSD} \\
(\mathrm{A} 2)\end{array}$ & $\begin{array}{l}\mathrm{RSD} \\
(\mathrm{A} 1 / \mathrm{A} 2)\end{array}$ & $\begin{array}{l}\mathrm{RSD} \\
(\mathrm{t} 1)\end{array}$ & $\begin{array}{l}\mathrm{RSD} \\
(\mathrm{t} 2)\end{array}$ & $\begin{array}{l}\mathrm{RSD} \\
\left(\mathrm{C}_{\mathrm{s}}\right)\end{array}$ \\
\hline $\begin{array}{c}\text { Repeata- } \\
\text { bility }^{\mathrm{c})}\end{array}$ & 10 & 3.40 & 4.43 & 5.15 & 1.69 & 1.78 & 2.89 \\
& 90 & 5.36 & 5.74 & 4.11 & 2.56 & 2.65 & 5.08 \\
& 90 & 4.45 & 4.76 & 1.17 & 3.14 & 3.26 & 4.56 \\
Reproduci- $_{\text {bility }^{\mathrm{d})}}$ & 10 & 5.33 & 4.03 & 4.14 & 2.78 & 2.25 & 6.44 \\
& 40 & 5.05 & 3.30 & 3.38 & 4.68 & 4.67 & 2.46 \\
& 90 & 5.43 & 7.47 & 4.94 & 4.40 & 4.17 & 3.10
\end{tabular}

$A 1$ and $A 2$ are the peak areas of the first and second migrating enantiomers, respectively.

$\mathrm{t} 1$ and $\mathrm{t} 2$ are the migration times corresponding to the first and second migrating enantiomers, respectively.

a) Conditions as in Fig. 3

b) Concentration of terbutaline in a solution prepared by dilution of the commercial syrup $(\mu \mathrm{g} / \mathrm{mL})$

c) RSD values determined for six consecutive injections

d) RSD values determined for three different days (each injection was made by duplicate)

To evaluate the precision of the CE method (Table 2), repeatability and reproducibility were studied. The repeatability in peak area and migration time of the enantiomers and for the terbutaline content was determined (as RSD) for six consecutive injections of each of three dilutions in DMSO of the pharmaceutical preparation (a syrup solution with $300 \mu \mathrm{g} / \mathrm{mL}$ of terbutaline) of concentrations of 10,40 , and $90 \mu \mathrm{g} / \mathrm{mL}$ in terbutaline. RSD was less than $3.3 \%$ for the migration time of the enantiomers, $5.7 \%$ for peak area of the enantiomers, and $5.1 \%$ in total concentration. On the other hand, reproducibility in peak area and migration time of the enantiomers and for the terbutaline content in the pharmaceutical preparation was measured as the RSD obtained in three different days (injections by duplicate) for three different sample dilutions of the syrup $(10,40$, and $90 \mu \mathrm{g} / \mathrm{mL}$ of terbutaline). As it can be observed in Table 2, the RSD values obtained were less than $7.5 \%$ for the peak area of each enantiomer, $4.7 \%$ for the migration times of the enantiomers, and $6.4 \%$ for the terbutaline concentration calculated.

Accuracy of the method was evaluated by calculating the recovery (\%) of terbutaline content found when a known quantity of terbutaline standard was added to a diluted solution of the syrup with $10 \mu \mathrm{g} / \mathrm{mL}$ of terbutaline. In order to evaluate the accuracy of the method, two samples with a total concentration of 10 and $40 \mu \mathrm{g} / \mathrm{mL}$ of terbutaline were injected by duplicate in three different days, and the corresponding concentration obtained by the EKC method was calculated by interpolating on the calibration curve injected the same day. Table 3 groups the recovery (\%) of the terbutaline content determined in three different days, being the mean recovery close to $98 \%$.

Table 3. Accuracy estimated as recovery (\%) of the terbutaline content ${ }^{\mathrm{a})}$

\begin{tabular}{|c|c|c|c|c|c|c|c|}
\hline Sample & Day & Calibration curve $\left.{ }^{b}\right)$ & $C_{\mathrm{s}}{ }^{\mathrm{c})}$ & $C_{\text {terbutaline }}{ }^{d)}$ & $C_{T^{e}}{ }^{e}$ & $C_{C E}^{f)}$ & $\begin{array}{l}\text { Recovery } \\
(\%)\end{array}$ \\
\hline \multirow{6}{*}{$\begin{array}{l}\text { Commercial syrup } \\
\text { containing } \\
\text { terbutaline } \\
\text { sulfate } \\
(300 \mu \mathrm{g} / \mathrm{mL})\end{array}$} & 1 & $y=0.3540 \times-0.1376$ & 10 & 0 & 10 & 10.46 & 104.57 \\
\hline & & $(n=8 ; r=0.999)$ & 10 & 30 & 40 & 38.19 & 95.47 \\
\hline & 2 & $y=0.3484 \times+0.0254$ & 10 & 0 & 10 & 9.20 & 91.97 \\
\hline & & $(n=5 ; r=0.999)$ & 10 & 30 & 40 & 40.04 & 100.10 \\
\hline & 3 & $y=0.3487 \times-0.0821$ & 10 & 0 & 10 & 9.98 & 99.84 \\
\hline & & $(n=5 ; r=0.997)$ & 10 & 30 & 40 & 38.69 & $\begin{array}{l}96.72 \\
\text { Mean value } \\
\text { (RSD \%) } \\
98.11(4.45)\end{array}$ \\
\hline
\end{tabular}

a) Conditions as in Fig. 3

b) Calibration curves obtained in different days ( $n$, number of points considered for the calibration curve; $r$, correlation coefficient)

c) Concentration of terbutaline in a solution prepared by dilution of the commercial syrup $(\mu \mathrm{g} / \mathrm{mL})$

d) Concentration of the terbutaline standard added $(\mu \mathrm{g} / \mathrm{mL})$ to the sample

e) Total concentration of terbutaline $(\mu \mathrm{g} / \mathrm{mL})$ in the analyzed solution

f) Concentration of terbutaline $(\mu \mathrm{g} / \mathrm{mL}$ ) determined by the CE method (average of two determinations) 


\section{Concluding remarks}

A screening of various chiral selectors (bile salts alone or mixed with sodium docecyl sulfate or neutral, anionic, or cationic $\mathrm{CD}$ derivatives) under different experimental conditions (buffer nature and $\mathrm{pH}$ ), has shown that $\mathrm{PM}-\beta-\mathrm{CD}$ is the most useful chiral selector for the enantiomeric separation of the basic drugs studied in this work (epinephrine, terbutaline, clenbuterol, and salbutamol). A study on the influence of the PM- $\beta-C D$ concentration showed that although the maximum enantiomeric resolution value depended on the basic drug investigated, $30 \mathrm{~mm}$ is the most appropriate value considering all drugs studied. In addition, the enantioseparation obtained for these compounds with PM- $\beta-C D$ was highly influenced by the temperature, observing an increase in the enantiomeric resolution when decreasing the temperature. Finally, a study on the influence of the applied voltage enabled to select $20 \mathrm{kV}$ as the most appropriate value. As a result, a $25 \mathrm{~mm}$ acetate buffer $(\mathrm{pH} 5)$ containing $30 \mathrm{~mm}$ PM- $\beta-\mathrm{CD}$ at a temperature of $15^{\circ} \mathrm{C}$ and an applied voltage of $20 \mathrm{kV}$ enabled the fast enantiomeric resolution, in less than $3 \mathrm{~min}$, of five basic drugs: epinephrine, norepinephrine, terbutaline, clenbuterol, and salbutamol.

Due to the short analysis time required for the separation of terbutaline with the $\mathrm{CE}$ system based on $25 \mathrm{~mm}$ acetate buffer at $\mathrm{pH} 5$ together with $30 \mathrm{~mm} \mathrm{PM}-\beta-\mathrm{CD}$ at $15^{\circ} \mathrm{C}$ and $20 \mathrm{kV}$, the validation of this method for the quantitation of terbutaline in a pharmaceutical preparation (a syrup) was performed. Results obtained indicated good precision in terms of peak area and migration time of the enantiomers and an acceptable accuracy in the determination of the total content of terbutaline.

The authors thank the Comisión Interministerial de Ciencia y Tecnología (Spain) for project PB98-0709.

Received February 9, 2001

\section{References}

[1] Chankvetadze, B., Capillary Electrophoresis in Chiral Analysis, John Wiley \& Sons, Chichester 1997.

[2] Okafo, G. N., Bintz, C., Clarke, S. E., and Camilleri, P., J. Chem. Soc. Chem. Commun. 1992, 1189-1192.

[3] Okafo, G. N., Camillieri, P., J. Microcol. Sep. 1993, 5, 149155.

[4] Nishi, H., J. High Resolut. Chromatogr. 1995, 18, 659-663.

[5] Lin, M., Wu, N., Barker, G. E., Sun, P., Huie, C. W., Hartwick, R. A., J. Liq. Chromatogr. 1993, 16, 3667-3674.

[6] Sheppard, R. L., Tong, X., Cai, J., Henion, J. D., Anal. Chem. 1995, 67, 2054-2058.

[7] Otsuka, K., Terabe, S., J. Liq. Chromatogr. 1993, 16, 945-953.

[8] Aboul-Enein, H. Y., Efstatiade, M. D., Baiulescu, G. E., Electrophoresis 1999, 20, 2686-2690.
[9] Ingelse, B. A., Sarmini, K., Reijenga, J. C., Kenndler, E., Everaerts, F. M., Electrophoresis 1997, 18, 938-942.

[10] Hong, S., Lee, C. S, Electrophoresis 1995, 16, 2132-2136.

[11] Rogan, M. M., Altria, K. D., Goodall, D. M., Electrophoresis 1994, 15, 808-817.

[12] Koppenhoefer, B., Epperlein, U., Christian, B., Lin, B., Ji, Y., Chen, Y., J. Chromatogr. A 1996, 735, 333-343.

[13] Pálmarsdóttir, S., Edholm, L. E., J. Chromatogr. A 1994, 666, 337-350.

[14] Quang, C., Khaledi, M. G., J. Chromatogr. A 1995, 692, 253265.

[15] Armstrong, D. W., Chang, L. W., Chang, S. S. C., J. Chromatogr. A 1998, 793, 115-134.

[16] Aumatell, A., Wells, R. J., Wong, D. K. Y., J. Chromatogr. A 1994, 686, 293-307.

[17] Toussaint, B., Hubert, Ph., Tjaden, U. R., Van der Greef, J., Crommen, J., J. Chromatogr. A 2000, 871, 173-180.

[18] Pierre, L. A. S., Sentell, K. B., J. Chromatogr. B 1994, 657, 291-300.

[19] Jin, L. J., Li, S. F. Y., J. Chromatogr. B 1998, 708, 257-266.

[20] Guo, Y., Imahori, G. A., Colón, L. A., J. Chromatogr. A 1996, 744, 17-29.

[21] Gausepohl, C., Blaschke, G., J. Chromatogr. B 1998, 713, 443-446.

[22] Altria, K. D., Harden, R. C., Hart, M., Hevizi, J., Hailey, P. A., Makwana, J. V., Portsmouth, M. J., J. Chromatogr. 1993, 641, 147-153.

[23] Heuermann, M., Blaschke, G., J. Chromatogr. 1993, 648, 267-274.

[24] Bingcheng, L., Xiaofeng, Z., Epperlein, U., Schwierskott, M., Schlunk, R., Koppenoefer, B., J. High Resol. Chromatogr. 1998, 21, 215-224.

[25] Altria, K. D., Goodall, D. M., Rogan, M. M., Chromatographia 1992, 34, 19-24.

[26] de Boer, T., Ensing, K., J. Pharm. Biomed. Anal. 1998, 17, 1047-1056.

[27] Esquisabel, A., Hernández, R. M., Gascón, A. R., Igartua, M., Calvo, B., Pedraz, J. L., J. Pharm. Biomed. Anal. 1997, 16, 357-366.

[28] Altria, K. D., Goodall, D. M., Rogan, M. M., Electrophoresis 1994, 15, 824-827.

[29] Gratz, S. R., Stalcup, A. M., Anal. Chem. 1998, 70, 51665171.

[30] Gahm, K. H., Chang, L. W., Armstrong, D. W., J. Chromatogr. A 1997, 759, 149-155.

[31] Izumoto, S. I., Nishi, H., Electrophoresis 1999, 20, 189-197.

[32] Glukhovskiy, P., Vigh, G., Electrophoresis 2000, 21, 20102015.

[33] Fillet, M., Bechet, I., Hubert, Ph, Crommen, J., J. Pharm. Biomed. Anal. 1996, 14, 1107-1114.

[34] Tang, Y. F., Wu, H. L., Wu, S. M., Chen, S. H., Kou, H. S., J. Microcol. Sep. 2000, 12, 366-370.

[35] Jakubetz, H., Juza, M., Schurig, V., Electrophoresis 1997, 18, 897-904.

[36] Altria, K. D., Goodall, D. M., Rogan, M. M., Electrophoresis 1994, 15, 824-827.

[37] Goodman Gilman A., Rall T. W., Nies, A. S., Taylor, P., The Pharmacological Basis of Therapeutic, Pergamon Press, Elmsford, NY, USA 1990.

[38] Microsoft Excel 7.0, Microsoft Corporation, 1985-1997.

[39] García-Ruiz, C., Marina, M. L., Electrophoresis 2000, 21, 1565-1573.

[40] Miller, J. C., Miller, J. N., Addison-Wesley Iberoamericana, $2^{\mathrm{a}}$ Edición, Wilmington, DE, USA 1993. 